\title{
РЕПРЕЗЕНТАЦИЯ СЛОЖНЫХ СТРАНИЦ ВЕЛИКОЙ ОТЕЧЕСТВЕННОЙ ВОЙНЫ В МУЗЕЙНОМ ПРОСТРАНСТВЕ МУЛЬТИМЕДИЙНЫМИ СРЕДСТВАМИ (НА ПРИМЕРЕ МУЗЕЯ «РОССИЯ - МОЯ ИСТОРИЯ»)
}

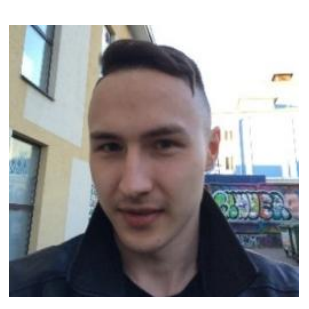

НI.P. Баговеев, магистр I курса историко-политологического факультета Пермского государственного начионального исследовательского университета, Пермь bagoveevshamil@yandex.ru

Аннотация. Великая Отечественная война является grand narrative в памяти российского общества. При этом она вырвана из контекста существования СССР. «Сложные страницы» войны репрезентируются отдельно от grand narrative в «местах памяти», в том числе и в музейном пространстве. Это фрагментарность в рамках «клиповой культуры» приводит к искажению памяти о важных событиях прошлого. Рассматривая музей как важный инструмент коммеморации, относящихся к научному полю memory studies, исследуется репрезентация памяти о «сложных страницах» Великой Отечественной войны в музее «Россия - Моя история» с помощью мультимедийных средств.

Ключевые слова: grand narrative, места памяти, клиповая культуpa, коммеморация, memory studies, коллективная память.

\section{THE REPRESENTATION OF THE DIFFICULT PAGES OF THE GREAT PATRIOTIC WAR IN MUSEUM SPACE BY MULTIMEDIA MEDIA (ON THE EXAMPLE OF THE MUSEUM «RUSSIA - MY HISTORY»)}

\author{
Shamil Bagoveev, \\ 1 st year master of the Faculty of History and Politics \\ Perm State National Research University, Perm \\ bagoveevshamil@yandex.ru
}

\footnotetext{
Abstract. The Great Patriotic War is a grand narrative in the memory of Russian society. At the same time, it was take out of context of the existence of the USSR. «Difficult pages» of the war are represented separately from the 
grand narrative in "places of memory», including in the museum space. This fragmentation within the framework of «clip culture» leads to distortion of the memory of important events of the past. Considering the museum as an important instrument of commemoration related to the scientific field of memory studies, the representation of the memory of the «difficult pages» of the war in the museum «Russia - My history» using multimedia means is investigated.

Keywords: grand narrative, places of memory, clip culture, commemoration, memory studies, collective memory.

Великая Отечественная война оставила неизгладимый след в истории нашего государства и остается grand narrative в построение идентичности у российского общества. При этом она включает в себя огромное множество противоречивых нарративов (ГУЛАГ, штрафные батальоны, депортации народов). В силу этого нужно очень осторожно подходить к интерпретации нашего прошлого, но, к сожалению, это происходит не всегда однозначно, вызывая острые дискуссии в научной среде и в медиапространстве. Особое место ретранслятора исторической памяти занимают музеи. Одним из последних проектов в сфере социально-культурной репрезентации прошлого стал проект «Россия - Моя история», вызвавший множество диаметральных оценок. Являясь по сути продуктом клиповой культуры - термин, предложенный Элвином Тоффлером, - музей «Россия - Моя история» прививает его посетителям клиповое мышление. В силу своих особенностей оно не способно в полной мере помочь в интерпретации нарратива Великой Отечественной войны и создает искаженную картину у посетителей о событиях прошлого.

В 90-е гг. новая российская правящая элита столкнулась с проблемами поиска идентичности для молодого государства. Это был закономерный этап в процессе декоммунизации в странах Восточной Европы. В случае с Россией он развивался по другому сценарию, в отличие от других бывших членов Варшавского договора, где происходили «бархатные революции». Поиск идентичности в условиях складывания рыночной экономики был сложен и противоречив. В политической сфере наблюдалась острая борьба между правящим истеблишментом и жаждущими реванша коммунистами, апогеем которой стали президентские выборы 1996 г. Это борьба во многом нашла свое отражение в символической политике или в более узком смысле - в исторический политике, ко- 
торая своими методологическими корнями уходит в знаменитой «спор историков» в 80-е гг. в ФРГ о поиске национальной идентичности.

Только во времена президентства В.В. Путина идентичность удалось более или менее сформировать. Алейда Ассман приводит следующие слова из статьи «Трансформации нового режима времени»: «Русскую революцию 1917 года Путин свел к простому перевороту, и главный праздник страны, 7 ноября, был стерт из памяти русской культуры. Его заменили другим праздником, 4 ноября, спешно сфабрикованным путинскими историками, которые, словно по волшебству, создали никому не известное (и, возможно, в значительной степени высосанное из пальца) событие XVII века, чтобы предложить населению страны новую, ближайшую по календарю к давно уже любимому национальному празднику, дату» [1].

Пьер Нора в своей magna opus «Места памяти» заключает, что память - это изначально субъективная операция. «В отличие от истории, память - это эмоциональное переживание, связанное с реальным или воображаемым воспоминанием и допускающее всевозможные манипуляции, изменения, вытеснения, забвения» [2]. Соглашаясь с ним, мы в дальнейшем оперируем понятием памяти в научном поле memory study и используем концепцию Пьера Нора о «местах памяти».

Согласно теории этапов развития цивилизации М. Маклюэна, «общество, находясь на современном этапе развития, трансформируется в “электронное общество” или “глобальную деревню” и задает посредством электронных средств коммуникации многомерное восприятие мира. Развитие электронных средств коммуникации возвращает человеческое мышление к дотекстовой эпохе, и линейная последовательность знаков престает быть базой культуры» [3].

Можно ли тогда считать происходящие перемены в восприятии мира регрессом общества и упадком культуры? Неужели человечество возвращается в первобытные времена, когда наскальная живопись была чуть ли не единственным способом оставить после себя какую-либо память? Возможно, все дело в двойственности. Прогресс, который неустанно сопровождает нашу жизнь, перестает быть благом. Общество потребления или технократия во всех сферах жизни стали бессменной основой социокультурных 
паттернов современного общества, которое при этом перестает развиваться нравственно и морально. Ж. Бодрийяр заключает, что «общество потребления» - это не пассивное состояние поглощения или присвоения, это - основополагающий процесс социокультурной жизнедеятельности современного буржуазного общества [4].

Если переложить трансформацию методов восприятия в контекст современных российских репрезентаций событий прошлого, в том числе нарратива Великой Отечественной войны, возникают мысли о «потреблении» памяти в рамках «клиповой культуры» или, в более узком смысле, в модели «клипового мышления». Впервые феномен «клиповой культуры» (от англ. to clip обрезать, обрывать, делать вырезки) как принципиально нового явления был отмечен американским футурологом Э. Тоффлером, рассматривающим данное понятие в качестве составляющей общей информационной культуры.

Согласно Э. Тоффлеру, клиповая культура - это культура коротких сообщений, которая создается за счет свободного зэпинга - быстрого переключения между различными каналами информации, например, как это происходит при переключении телевизионных каналов [5]. Обобщая телевидение, радио, Интернет под одним понятием «медиа», можно цитировать слова Маршала Маклюэна, что медиа - это не просто пассивные каналы информации. Они поставляют материал для размышления, но они также формируют и сам процесс мышления [3]. Музей «Россия - Моя история»- это пример проникновения медийности в музейное пространство.

Используя методологию Пьера Нора, утверждение о том, что музей является «местом памяти», явственно имеет смысл. Материальные предметы, хранящиеся там, оборачиваются символическим, даже сакральным смыслом. Пьер Нора приводит следующее высказывание: «"Места памяти” являются местами в трех смыслах - материальном, символическом и функциональном. Но эти модусы мест памяти весьма взаимосвязаны: даже место, внешне совершенно материальное, как, например, архивное хранилище, не является местом памяти, если воображение не наделит его символической аурой» [2]. Также музей становится функциональным местом, так как, например, обладает образовательной функцией. 
При конкретизации вышесказанного на примере музея «Россия - Моя история» возникают вопросы о применении концепции «мест памяти» к этому музейному пространству. По замечанию П. Нора, музей относится к «базовым инструментам исторической работы и к наиболее символическим объектам нашей памяти» [2]. Безусловно, музей «Россия - Моя история» относится к постмодернистской модели организации музейного пространства и во многом порывает с традициями классического музея, который существовал с конца XIX в. до конца XX в.

Для нас важна оценка процесса репрезентации «сложных страниц» Великой Отечественной войны в музее «Россия - Моя история» через призму памяти. Именно памяти, а не истории, потому что каждый из нас может интерпретировать события из прошлого, которое «принадлежит многим людям, начиная с тех, кто пережил недавние события, и особенно тех, кто пострадал от них» [2]. К сожалению, все меньше людей, причастных к событиям Великой Отечественной войны, остается в живых, но это неизбежный закон жизни. Если концепция коллективной памяти реализуется, и автор статьи и его сверстники, родившиеся в конце 80-х начале 90-х гг., станут последним поколением, которые застанут участников войны живыми, то репрезентация прошлого в рамках устной истории прервется, и станет гораздо сложнее сохранить объективность в интерпретации Великой Отечественной войны. Хотя объективность, являющая непостижимым идеалом в исторической науке и тем более в истории памяти, меньше всего применима в интерпретации прошлого.

Пьер Нора и его концепция «мест памяти» относится к научному полю memory studies. Один из краеугольных камней memory studies - это соотношение коллективной и индивидуальной памяти. Впервые термин коллективной памяти внес в научный оборот французский социолог Морис Хальбвакс, ученик Эмиля Дюркгейма. Коллективная память - это представление о прошлом, разделяемое и конструируемое членами социальной общности [6].

«Историческая память», «социальная память», «коллективная память» часто представлены, как тождественные дефиниции, но при этом они используются в разных дискурсах. Социальная психология употребляет понятие «коллективная память», социологи предпочитают понятие «социальная память». «Историческая 
память» является прерогативой представителей социокультурной антропологии.

В этой статье мы оперируем понятием «коллективная память», так как рассматриваем исследовательскую проблему отчасти через призму социальной психологии. При этом не ставим цель использовать методологию когнитивной психологии, в которой память является одним из ключевых понятий, и даже не стремимся задействовать нейробиологию. По крайней мере не в рамках данного исследования.

Для нас важно в первую очередь, как коллективная память входит в контекст социальных наук. Опять же существование этой дефиниции в научном языке ставится под сомнение многими учеными, например Р. Козеллеком, настаивающим на том, что память может быть только индивидуальной [7]. В связи с этим будет уместно использовать понятие памяти, не разделяя ее на коллективную или индивидуальную. Рассматривая ее как важный инструмент создания социальной идентичности и сплочения общностей, необходимо обратиться к Э. Дюркгейму, основоположнику социологической науки, и его работе «Элементарные формы религиозной жизни».

Именно Дюркгейм в своей книге описал вид религиозного ритуала, практиковавшийся у австралийских племен, репрезентативный или коммеморативный ритуал, цель которого состоит в репрезентации мифической памяти о предках и создании чувства единения или определенной идентичности. Их этого следует, что именно Дюркгейм вводит понятие «коммеморация» или «коммеморативные практики» - способ укрепления и передачи памяти о прошлом. Это способствует формированию коллективной памяти о событиях прошлого, создает единство общества и преемственность поколений [8]. Музей «Россия - Моя история»- это воплощение коммеморативных практик в материальной оболочке, как изначально планировали его создатели. Вопрос об объективности этого суждения остается дискуссионным и подвергается верификации в данном исследовании.

Во многом в основу анализа положена известная книга Маршалла Маклюэна «Галактика Гутенберга», в которой автор анализирует историю восприятия информации людьми от первобытного общества до 60-х гг. XX в. и противопоставляет устную и 
письменную культуры. Стилистика данной книги очень необычна. Не являясь по своей сути научной монографией, она складывается как компиляция художественных текстов и выдержек из научных статей. Для книги характерен принцип фрагментарности, каждая глава которой может быть прочитана в произвольном порядке, что является основополагающим признаком постмодернистской литературы. Для работы Маклюэна свойственна гипертекстуальность, текст насыщен отсылками и аллюзиями, которые могут превратиться в ссылки, если поместить текст в интернет-пространство, превратив книгу Маклюэна в набор различных лонгридов. В наше время письменный текст перестает быть отражением окружающего мира, а это значит, что меняется образ мышления людей. Они перестали воспринимать текст как главный носитель информации. Устная культура ставит во главу угла различные медиа, в частности Интернет. Именно он является главным катализатором формирования «клиповой культуры», в которой на первый план выходят визуальные образы, представленные в музее «Россия - Моя история». При всех своих достоинствах «клиповая культура» имеет ряд недостатков, одним их которых является фрагментарность восприятия информации. Индивиду сложно собрать разрозненные кусочки пазла в единую мозаику.

Непосредственному анализу подверглись две экспозиция «Память поколений» и «От великих потрясений до Великой Победы: 1917-1945 годы». Первая экспозиция была посвящена памяти о Великой Отечественной войне. Главными и единственными ретрансляторами памяти были картины известных художников XX в. о войне. 200 шедевров живописи были разделены на несколько разделов: «Фронт», «Тыл и оккупация», «Победа», «Павшим вечная слава», «Старые раны. 1960-е», «Эхо прошедшей войны. 1970-е», «Во имя жизни. 1990-2010-е». К сожалению, в картинах известных художников не было обнаружено отражение «сложных страниц» Великой Отечественной войны, таких как ГУЛАГ, штрафные батальоны, депортация народов. Так это и закономерно. Откуда этим нарративам взяться на картинах, написанных в годы войны и послевоенное время. В то время не было принято изображать «сложные страницы» на полотнах живописи. То есть посетители, придя в музей, не будут помнить об этом. 
Вторая экспозиция охватила период от Октябрьской революции до конца Великой Отечественной войны. С помощью мультимедийных средств у посетителей есть возможность ознакомиться с 700 архивными документами, 3000 информационных статей, 1000 часов документальной хроники, пятью авторскими инсталляциями. Экспозиция предлагает взглянуть на эпоху Советов без «розовых очков», ознакомиться со сведениями из архивов спецслужб под грифом «секретно» и «совершенно секретно». Концептуально выставка провозглашает народ строителем великого государства.

Как и в случае с первой экспозицией, попытки осмысления «сложного прошлого» в контексте Великой Отечественной войны не наблюдалось. Лишь в экспозиции «Россия - Моя история. 19452016» был мультимедийный стенд, посвященный культу личности Сталина, в котором репрезентовались «сложные страницы» войны: ГУЛАГ, депортация народов, религиозная политика государства в годы войны. Это было представлено вне контекста главного события русской истории XX в., которое словно вычистили от того, что люди современности должны были помнить. Складывалась картина, что «сложные страницы» войны не могут состоять в grand narrative. Народ не виноват в том, что это было. Виновато советское руководство во главе со Сталиным. Всего один стенд, несколько тысяч знаков, посвященных травмирующей памяти о прошлом, связанной с трагическими событиями Великой Отечественной войны, словно маленький пазл, фрагмент в огромной мозаике нашей истории.

Музей «Россия - Моя история» поражает своей мультимедийностью и рассчитан на четыре типа восприятия информации человеком, но их степень воздействия при этом отличается. В первую очередь экспозиция музея рассчитана на приверженцев визуального типа восприятия. Дальше идут аудиалы, для которых информацию можно прослушать с помощью аудиоустройств. Кинестетикам сложно будет усвоить информацию, так как в плане эмоционального заряда посещения музейного пространства оставляют желать лучшего. Посещение государственного музея Аушвиц - Биркенау может оказать сильнейшее воздействие на кинестетиков. Так же, как, например, посещение музея «Пермь-36». В исследуемом музее нет составляющих, которые могли бы эмо- 
ционально и чувственно взбудоражить посетителей. И четвертый тип - это дигитал, для которого будет сложно систематизировать и структурировать информацию, полученную в музейном пространстве.

Исходя из вышесказанного, можно сделать вывод, что для музея «Россия - Моя история» предпочтительной целевой аудиторией являются визуалы. Оказавшись там, словно попадаешь в интерфейс мобильного телефона. Информация подана в виде картинок с выпадающим текстом. Посетитель бродит по музею и скринит информацию на touch-экранах информационных стендов, словно экспонаты музея XXI в.

Упоминание «сложных страниц» Великой Отечественной войны в музейном пространстве, безусловно, присутствует, но за рамками контекста самой войны. Это искажает картину образов прошлого, показанную через призму ретранслятора памяти, в материальном воплощении музея «Россия - Моя история». При этом в каждом крупном городе присутствует такое типовое музейное пространство. Коллективная память россиян о grand narrative $\mathrm{Be}-$ ликой Отечественной войны формируется в рамках клипового мышления и не способна в полной мере сформировать картину произошедших событий.

\section{Список литературы}

1. Ассман А. Трансформация нового режима времени / пер. с англ. В. Кучерявкин // Август, XX век: Трансформация жизни частного человека в эпоху социальных катаклизмов: коллективная монография: в 2 т. - М.: Новое литературное обозрение, 2014. T. 1. - C. 16-31.

2. Нора П. Проблематика мест памяти // Франция-память. СПб: Изд-во Санкт-Петербургского ун-та, 1999. - С. 17-50.

3. Маклюэн М. Галактика Гуттенберга: Становление человека печатающего. - М.: Академический проект, 2005.

4. Бодрийяр Ж. Система вещей. - М.: Рудомино, 2001. - 231 с.

5. Тоффлер Э. Шок будущего: пер. с англ. - М.: АСТ, 2002. $557 \mathrm{c}$.

6. Хальбвакс М. Социальные рамки памяти. - М.: Новое издательство, 2007. - 346 с. 
7. Ассман А. Новое недовольство мемориальной культурой. М.: Новое литературное обозрение, 2016. - С. 17-20. РАНХиГС, 2018. - $736 \mathrm{c}$.

8. Дюркгейм Э. Элементарные формы религиозной жизни: тотемическая система в Австралии = Les Formes élémentaires de la vie religieuse: le système totemique en Australie / пер. с франц. А. Апполонова и Т. Котельниковой; под науч. ред. А. Апполонова. - М.: Изд. дом «Дело», 2018. 